\title{
Agronomic Performance and Yield Stability of Large Red Bean Genotypes Using AMMI Model in Midlands of Bale Zone, South-Eastern Ethiopia
}

\author{
Tadele Tadesse*, Gashaw Sefera, Belay Asmare, Amanuel Teklaign \\ Oromia Agriculture Research Institute, Sinana Agriculture Research Center, Bale-Robe, Ethiopia \\ Email address: \\ tadyeko20@gmail.com (T. Tadesse), tadeleta20@yahoo.com (T. Tadesse) \\ ${ }^{*}$ Corresponding author
}

\section{To cite this article:}

Tadele Tadesse, Gashaw Sefera, Belay Asmare, Amanuel Teklaign. Agronomic Performance and Yield Stability of Large Red Bean Genotypes Using AMMI Model in Midlands of Bale Zone, South-Eastern Ethiopia. Chemical and Biomolecular Engineering.

Vol. 3, No. 3, 2018, pp. 35-39. doi: 10.11648/j.cbe.20180303.13

Received: September 3, 2018; Accepted: September 17, 2018; Published: October 24, 2018

\begin{abstract}
In order to identify the agronomic performance and yield stability of the large red bean genotypes, sixteen large red bean genotypes were evaluated in the midlands of bale zone at Goro, Ginir and Dellomena for two consecutive years 2016 and 2017 main cropping season. The genotypes were arranged in randomized complete block design with four replications having plot size of $6.4 \mathrm{~m}^{2}$ (4 rows at $40 \mathrm{~cm}$ spacing and $4 \mathrm{~m}$ long). The analysis of variance revealed that highly significant variation for environment, genotypes and year X Location, whereas GEI (Genotypes by Environment interaction) showed significant variation for mean grain yield. Of the total sum squares of variation observed, $38.33 \%$ was accounted for environment followed by genotypes $11.53 \%$ and GEI $4.51 \%$. The significant effect of GE interaction reflected on the differential response of genotypes in various environments and demonstrated that GE interaction had remarkable effect on genotypic performance in different environments. The application of AMMI model for partitioning the GE interaction effects showed that only the first two terms of AMMI were significant. In the AMMI analysis, out of the total GEI variation observed, the first AMMI explained $78.28 \%$ of the variation whereas $21.72 \%$ was accounted for the AMMI2. A combination of high grain yield potential, stabilityparameter of regression coefficient of unity and minimum deviation mean squares from regression identifies G4 as moderately stable genotype with high grain yield deserved to be promoted for possible release as commercial variety for the midlands of Bale zone and similar agro-ecologies.
\end{abstract}

Keywords: AMMI, Common Bean, GEI, Stability, Variation

\section{Introduction}

Common bean (Phaseolus vulgaris L.) is a major grain legume consumed worldwide for its edible seeds and pods. It is a highly polymorphic warm-season, herbaceous annual. There are 2 plant types: erect herbaceous bushes, up to 20-60 $\mathrm{cm}$ high; and twining, climbing vines up to $2-5 \mathrm{~m}$ long [1, 21]. It has a taproot with many adventitious roots. The stems of bushy types are rather slender, pubescent and manybranched. In twinning types, the stems are prostrate for most of their length and rise toward the end [6]. The leaves, borne on long green petioles, are green or purple in color and trifoliate. Leaflets are $6-15 \mathrm{~cm}$ long and $3-11 \mathrm{~cm}$ broad. The inflorescences are axillary or terminal, $15-35 \mathrm{~cm}$ long racemes. The flowers are arranged in pairs or solitary along the rachis, white to purple and typically papillonaceous [1 22]. Once pollinated, each flower gives rise to one pod. Pods are slender, green, yellow, black or purple in color, sometimes striped. They can be cylindrical or flat, straight or curved, 1-1.5 cm wide and up to $20 \mathrm{~cm}$ in length [22]. The pods may contain 4 to 12 seeds. The seeds are $0.5-2 \mathrm{~cm}$ long, kidney-shaped and highly variable in color depending on the variety: white, red, green, tan, purple, gray or black. It was domesticated independently in two centers of diversity, giving rise to two gene groups: Mesoamerican and Andean [3]. Differences between these groups can be checked in the morphology of the plant, seed size and type of phaseolin (reserve protein), among others. Andean lines have larger 
seed (100 seed weight above 30 grams) while Mesoamerican lines have smaller seed size (100 seed weight under 30 grams) [11]. When breeding new cultivars, the main obstacles is the presence of the genotype by environment interaction $(\mathrm{G} \times \mathrm{E})$. For the cultivation of common bean, numerous studies have shown the presence of such interaction, mainly for grain yield. Thus, one should seek alternatives to mitigate and/or take advantage from the interaction effects, including the use of methods for analysis of stability and adaptability, which provide detailed information about the behavior of cultivars, such as predictability and responsiveness to environmental variation [6]. Amongthe methods for studying stability, genotype recommendation index takes the combining concepts of both adaptability and stability into a single parameter [2 and 18]. Another methodology used in stability studies is the AMMI method (Additive Main Effects and Multiplicative Interactions) which allows a more detailed analysis of the $G$ $\mathrm{x} E$ interaction [24]. AMMI model is a popular extension of ANOVA for studying GE interaction [9]. This method extracts genotype and environment main effects and uses interaction principal components (IPCs) to explain patterns in the GE interaction or residual matrix, which provides a multiplicative model [20]. Therefore, the present study focused in identifying high yielding, stable large red bean genotypes for possible releases in the midlands of Bale zone, southeastern Ethiopia.

\section{Materials and Methods}

In order to identify stability of genotypes across the testing environments for grain yield, sixteen large red bean genotypes were evaluated for two consecutive years (2016-2017) at three midlands (Ginir, Goro and Dellomena) south eastern of bale zone, Ethiopia. At all locations randomized complete block design with four replications was used to evaluate the genotypes. Plot size used was $6.4 \mathrm{~m} 2$ (4 rows at $40 \mathrm{~cm}$ spacing and $4 \mathrm{~m}$ long). The two central rows were used for data collection. Combined analysis of variance LSD multiple range test were done using Cropstat9 software. The additive main effect and multiplicative interaction (AMMI) analysis was performed using the model suggested by [5]. The stability parameters like regression coefficient (bi), deviation from regression were also calculated using Cropsta9 program. AMMI Stability Value (ASV) the distance from the coordinate point to the origin in a two dimensional of IPCA1 scores against IPCA2 scores was computed by the model suggested by [19].
$\mathrm{ASV}=\sqrt{\left[\frac{\text { SSIPCA1 }}{\text { SSIPCA2 }}(\text { IPCA1score })\right]^{2}+\lceil I P C A 2\rceil^{2}}$

Where, $\frac{\text { SSIPCA1 }}{\text { SSIPCA2 }}$ is the weight given to the IPCA1 value by dividing the IPCA1 sum squares by the IPCA2 sum of squares

Genotype Selection Index (GSI) also calculated by the formula suggested by [8]. Here it is calculated by taking the rank of mean grain yield of genotypes $\left(\mathrm{RY}_{\mathrm{i}}\right)$ across environments and rank of AMMI stability value $\left(\mathrm{RASV}_{\mathrm{i}}\right)$.

$$
\mathrm{GSI}_{\mathrm{i}}=\mathrm{RASV}_{\mathrm{i}}+\mathrm{RY}_{\mathrm{i}}
$$

Table 1. Listsog large red bean genotypes used in the study.

\begin{tabular}{lll}
\hline SN & Genotpe Code & Genotype name \\
\hline 1 & G1 & DAB-525 \\
2 & G2 & DAB-531 \\
3 & G3 & DAB-538 \\
4 & G4 & DAB-523 \\
5 & G5 & DAB-498 \\
6 & G6 & DAB-504 \\
7 & G7 & DAB-491 \\
8 & G8 & DAB-537 \\
9 & G9 & DAB-488 \\
10 & G10 & DAB-518 \\
11 & G11 & DAB-496 \\
12 & G12 & DAB-526 \\
13 & G13 & DAB-507 \\
14 & G14 & DAB-522 \\
15 & G15 & Melkadima \\
16 & G16 & Red kidney \\
\hline
\end{tabular}

\section{Result and Discussion}

The combined analysis of variance revealed that highly significant variation for environment, genotypes, and year $\mathrm{x}$ location. GEI for grain yield was significant across the tested environment (Table 2). The pooled analysis detected significant differences $(\mathrm{p}<0.01)$ for environments and genotypes, which confirm the variation between the studied environments and genetic variability between lines (Table2). From the total variation observed $38.33 \%$ was accounted for the locations followed by genotypes $(11.53 \%)$. This implies the environment was much more contributes for the mean grain yield variation observed among the tested genotypes than other main effects. Significant variation for genotypes by environment interaction has also reported by [14, 17]. Similarly significant variation for the environment, genotypes and their interaction in wheat under normal and drought stress condition was also reported by [16].

Table 2. ANOVA for grain yield of 16 Large red bean genotypes.

\begin{tabular}{|c|c|c|c|c|}
\hline Source of Variation & Degree freedom & Sum Squares & Mean Squares & $\%$ of total variation \\
\hline YEAR (Y) & 1 & 11.3988 & $11.3988 * *$ & 9.13 \\
\hline Location (L) & 2 & 47.8791 & $23.9396^{* *}$ & 38.33 \\
\hline Replication & 3 & 0.889754 & 0.296585 & 0.71 \\
\hline Genotype (G) & 15 & 14.4049 & $0.960329 * *$ & 11.53 \\
\hline Y X L & 2 & 5.14002 & $2.57001 * *$ & 4.11 \\
\hline L X G & 30 & 5.63363 & $0.187788 *$ & 4.51 \\
\hline Y X L X G & 45 & 5.11653 & $0.113701 *$ & 4.09 \\
\hline TOTAL & 383 & 124.902 & 0.326115 & \\
\hline
\end{tabular}




\section{AMMI Analysis}

The combined analysis of variance showed that there are highly significant differences for environment, genotype and their interactions; combined analysis of variance and AMMI analysis is shown in Table 3. These result showed that $70.50 \%$ of the total variation is attributed for environmental effect. The genotype and the GEI effects olny contributed to $21.21 \%$ and $8.29 \%$ respectively. A large sum of squares for environments indicated that the environments were diverse, with large differences among environmental means causing variation in the plant grain yields. The AMMI model demonstrated the presence of $\mathrm{G} \times \mathrm{E}$ interactions, and this has been partitioned among the first and second IPCA (Interaction Principal Components Axes). Of the total variation observed, AMMI1 explained $78.28 \%$ of the interaction sum of squares; AMMI 2 captured $21.72 \%$ of the interaction sum of squares (Table 3). This indicates that the use of AMMI model fit the data well and justifies the use of AMMI2. According to [5 and 24] the first two interaction principal component axis best predictive model explains the interaction sum of squares. This made it possible to construct the biplot and calculate genotypes and environment effects [10, 12 and 23].

Table 3. Analysis of Variance for grain yield of large red common bean for the AMMI model.

\begin{tabular}{lllll}
\hline Source of variation & D.F. & S.S. & M.S.F & \%TSS \\
\hline Genotypes & 15 & 1.80062 & 0.120041 & 21.21 \\
LOCATIONS & 2 & 5.98489 & 2.99245 & 70.50 \\
TREATMENT X SITES & 30 & 0.704204 & 0.023474 & 8.29 \\
AMMI COMPONENT 1 & 16 & 0.551273 & 0.034455 & 78.28 \\
AMMI COMPONENT 2 & 14 & 0.15293 & 0.010924 & 21.72 \\
Total & 47 & 8.48971 & & \\
\hline
\end{tabular}

stability parameters mean grain yield, slope (bi) and deviation from regression, G4 showed maximum grain yield with bi close to unity and deviation from regression close to unity implying the genotype is more stable than others. Similar stability of rice genotypes for grain yield was also reported by [7] Furthermore, AMMI Stability Value (ASV), which is the distance from the coordinate point to the origin in a two dimensional scattergram of IPCA1 scores against IPCA2 score should also seen to decide the stability of a genotypes [19]. Accordingly, G8, G7 and G12 though they had the lowest ASV, they gave mean grain yield lower than the check and it was below than the grand mean. On the other hand G11, G1 and G4 had lower ASV as well as higher mean grain yield than the check and gave grain yield above the grand mean and showed wide adaptation over the testing environments (Table 4).

However, since stability in itself should not be the only parameter for selection, as the most stable genotype wouldn't necessarily gives the best yield performance [15], hence, simultaneous consideration of grain yield and ASV in single non-parametric index is needed or the Genotype Selection Index should be used to determine the stability of the genotypes by evaluating their mean grain yield and ASV..

Genotype Selection Index (GSI), when the rank of mean grain yield of genotypes across environments and rank of AMMI stability value considered to identify the tested genotypes in relation to stability, G11 and G4 had the lowest GSI values compared to the other genotypes and showed stable performance over the testing sites. However, the mean grain yield of G11 was equal to the check used in the study. Therefore, G4 was the stable and high yielder genotypes across the testing environments.

Mean of the genotypes over all environments ranged from $0.91 \mathrm{t} / \mathrm{ha}(\mathrm{G} 13)$ to $1.67 \mathrm{t} / \mathrm{ha}(\mathrm{G} 4)$ (Table 4). In relation to the

Table 4. Mean yield First and second IPCA and various yield-stability statistics investigated in large red common bean.

\begin{tabular}{|c|c|c|c|c|c|c|c|c|c|}
\hline Genotype code & MEAN & Rank & SLOPE (bi) & MS-DEV & IPCA1 & IPCA2 & ASV & Rank & GSI \\
\hline G1 & 1.38 & 6 & 0.927 & 0.23 & -0.05 & -0.01 & 0.19 & 5 & 11 \\
\hline G2 & 1.01 & 14 & 1.01 & 0.03 & -0.01 & -0.26 & 0.26 & 8 & 22 \\
\hline G3 & 1.38 & 5 & 1.31 & 0.45 & 0.22 & -0.05 & 0.79 & 11 & 16 \\
\hline G4 & 1.63 & 1 & 0.97 & 0.02 & 0.45 & 0.02 & 0.20 & 6 & 7 \\
\hline G5 & 1.43 & 4 & 0.618 & 0.01 & -0.26 & 0.16 & 0.96 & 13 & 17 \\
\hline G6 & 1.23 & 10 & 0.549 & 0.02 & -0.33 & -0.18 & 1.21 & 14 & 24 \\
\hline G7 & 1.17 & 12 & 0.95 & 0.35 & -0.04 & -0.04 & 0.14 & 3 & 15 \\
\hline G9 & 1.31 & 8 & 1.066 & 0.89 & 0.05 & 0.08 & 0.21 & 7 & 15 \\
\hline G10 & 1.38 & 7 & 1.313 & 0.03 & 0.21 & -0.29 & 0.80 & 12 & 19 \\
\hline G11 & 1.48 & 2 & 0.976 & 0.67 & -0.02 & 0.04 & 0.07 & 2 & 4 \\
\hline G12 & 1.2 & 11 & 1.055 & 0.78 & 0.04 & 0.07 & 0.17 & 4 & 15 \\
\hline G13 & 0.91 & 16 & 1.434 & 0.05 & 0.33 & 0.32 & 1.23 & 15 & 31 \\
\hline G14 & 1.27 & 9 & 0.904 & 0.01 & -0.08 & -0.12 & 0.30 & 9 & 18 \\
\hline G15 & 1.48 & 2 & 0.497 & 0.01 & -0.35 & 0.18 & 1.27 & 16 & 18 \\
\hline
\end{tabular}

Biplots: A graphical representation of grain yield showed in AMMI biplot, the relationship between the first interaction principal component axis (AMMI component 1) and mean of cultivars and locations [13], Cultivars and locations on the same equivalent line, obtain similar yields and a cultivar or location on the right-hand side of the midpoint of this axis gave higher yields than those on the left-hand side [24]. The Interaction Principal Component Axes (IPCA) scores of a 
genotype in the AMMI analysis indicate the stability of a genotype across environments. The closer the IPCA scores are to zero, the more stable the genotypes are across their testing environments. Basically, these biplots belong to two types: AMMI 1 and AMMI 2 [4]. In AMMI 1, the genotype and environment means are plotted on the abscissa, and the IPCA scores for the same genotypes and environments, on the ordinate. For interpretation of the AMMI 1 biplot, the magnitude and signal of the scores of the IPCA1 are observed; scores close to zero are characteristic of genotypes and environments, which contribute little to the interaction, that is, they are stable.

Accordingly G4, G11, G15, G5, G3, G1, G10 and G9 found in the right hand side of the graph meaning they gave mean grain yield higher than the grand mean. From the three environments Goro site had grain yield above the grand mean of the tested genotypes, G1, G3, G4, G10, and G11 were more adapted to Goro site. Genotypes found near the vertex of the biplot were considered as more stable to the testing sites. G7, G12, G14 and G9 were found in this stable category. The rest genotypes were more suited for the other two sites Ginir and Dellomena.

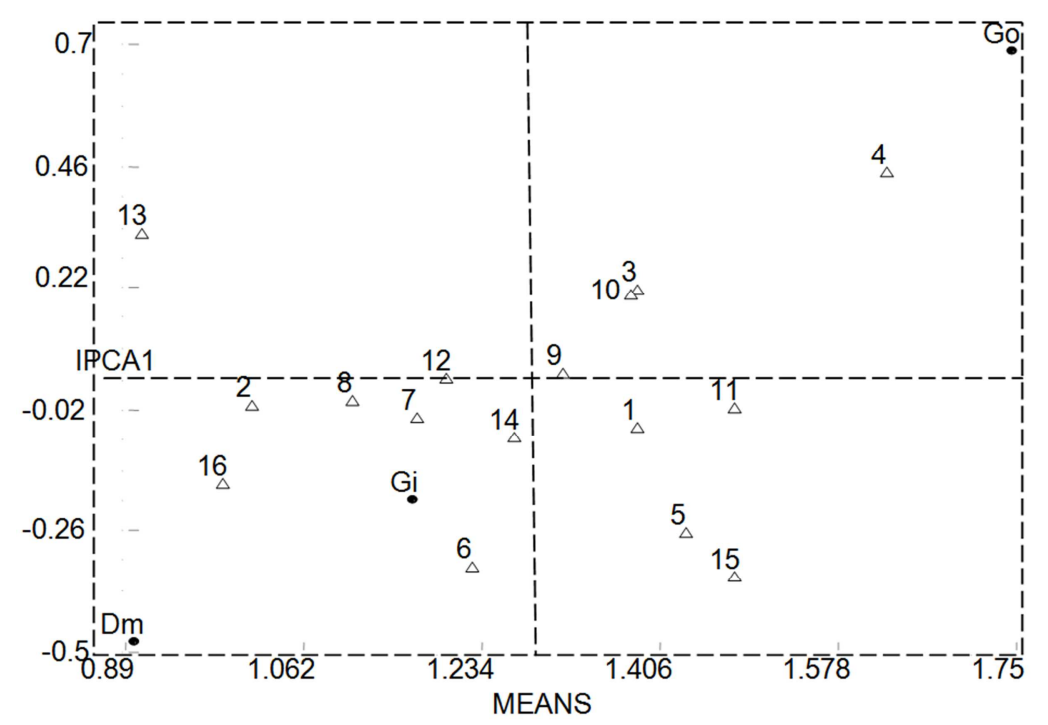

Figure 1. Biplot analysis of GEI based on AMMI 1 model for the PCA 1 scores and grain yield.

Regarding the other biplot, Figure 2, where IPCA 1 were plotted against IPCA 2scores, Genotypes G1, G7, G8, G11 G12 and G9 were found very close to the origin implies these genotypes were more stable than the rest of the genotypes and contributes less to the GEI variation. On the other hand G3 and G4 were found slightly far from the origin and considered as moderately stable genotypes. The rest genotypes which were found at very far distance away from the origin considered as unstable genotypes and contribute more to the GEI variation observed for grain yield. The results obtained by Figure 2 were in consistence with other stability parameters used to identify the stability of the tested genotypes.

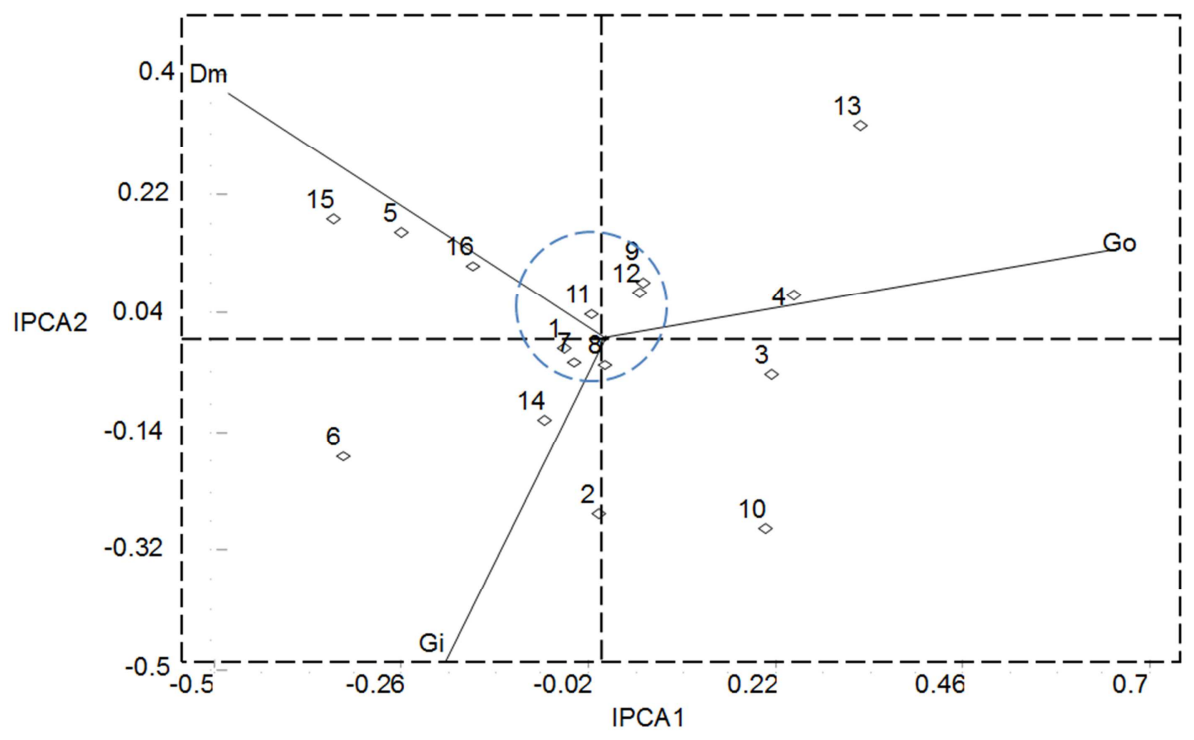

Figure 2. Biplot analysis of GEI based on AMMI 2 model for the first two IPCA scores. 


\section{Conclusion}

The analysis of variance of the 16 genotypes in 6 six environments showed that genotype $(\mathrm{G})$, location (L), cropyear $(Y)$ and their interaction were significant $(P<0.01)$ for grain yield. The AMMI model was very effective for studying GEI interaction. The first bilinear AMMI model terms accounted for $78.28 \%$ of the GEI. Regarding to the different stability parameters used to identify the stability of genotypes like slop (bi), deviation from regression, ASV and GSI Genotypes G1, G7, G8, G12, G9 and G11 were found to be more stable than the other tested genotypes but showed mean grain yield lower than the check. However, G4 had high mean grain yield and showed moderate stability across the tested environments. Therefore, G4 was selected as candidate variety to be verified in the coming bona/main cropping season across the testing sites.

\section{Acknowledgements}

Oromia Agricultural Research Institute for the financial support, Sinana Agricultural Research Center for providing all necessary facilities and Pulse and Oil Crops Research Case team staffs for trial management and data collection well acknowledge.

\section{References}

[1] Ecocrop, 2013. Ecocrop database. FAO, Rome, Italy.

[2] Annicchiarico, P. 1992. Cultivar adaptation and recommendation from alfafa trials in Northern Italy. Journal of Genetics and Plant Breeding, 46 pp.269-278.

[3] Beebe S, Gonzalez AV, Rengifo J. 2000. Research on trace minerals in the common bean. Food Nutr. Bull., 21: 387-391.

[4] Carbonell SA, Filho JA, Dias LA, Garcia AA, and Morais LK. 2004. Common bean cultivars and lines interactions with environments. Sci. Agric. (Piracicaba, Braz.) 61(2), 169-177.

[5] Crossa J, Fox PN, Pfeiffer WH, Rajaram S, and Gauch HG. 1991. AMMI adjustment for statistical analysis of an international wheat yield trial. Theor. Appl. Genet 81:27-37.

[6] Cruz CD, Regazzi AJ, Carneiro PCS. 2004. Modelos Biométricos Aplicados Ao Melhoramento Genético. 3. ed. Viçosa: Editora UFV. v.1, 480p.

[7] Amir AM, Nadali BJ, andKamal K. 2013. Environmental Responses and Stability Analysis for Grain Yield of Some Rice Genotypes. World Applied Sciences Journal 21 (1): 105108, 2013.

[8] Farshadfar E and Sutka J. 2003. Locating QTLs controlling adaptation in wheat using AMMI model. Cereal Res Commun 31: $249-254$.

[9] Gauch HG. 1992. Statistical Analysis of Regional Yield Trials: AMMI Analysis of Factorial Designs. Amsterdam, the Netherlands: Elsevier.

[10] Gauch HG and ZobelRW . 1996. AMMI Analysis of Yield
Trials. In: Kang MS, Gauch HG (eds) Genotype by environment Ineraction. CRC Press. Boca Raton, FL.

[11] Gonzales AM, Rodino AP, Santalla M, De Rona AM. 2009. Genetics of intra-gene pool and inter-gene pool hybridization for seed traits in common bean (Phaseolus vulgaris L.) germplasm from Europe. Field Crops Research, v.112, p.6676, 2009. http:// dx.doi.org/10.1016/j.fcr..02.003

[12] Kaya Y, Palta Ç and Taner S. 2002. Additive main effects and multiplicative interactions analysis of yield performances in bread wheat genotypes across environments. Turk J.of Agri. Forestry 26: 275-279.

[13] Kempton, RA. 1984. The use of biplots in interpreting variety by environment interactions. J. Agril. Sci., 103: 123-135.

[14] Mangi L, Raj K, Parvinder S, Shankar L, Harminder S, Hanuman S, Deepak B, Chiter M, and Raj G. 2017. Predicting Yield and Stability Analysis of Wheat under Different Crop Management Systems across Agro-Ecosystems in India. American Journal of Plant Sciences, 2017, 8, 1977-2012.

[15] Mohammadi R, Abdulahi A, Haghparast R and Armion M. 2007. Interpreting genotype environment interactions for durum wheat grain yields using non-parametric methods. Euphytica. 157: 239-251.

[16] Naroui MR, Abdul Kadir M, Rafii Y, Hawa J, Naghavi MR, and Farzaneh A. 2013. Genotype $\times$ environment interaction by AMMI and GGE biplot analysis in three consecutive generations of wheat (Triticumaestivum) under normal and drought stress conditions. AJCS 7(7):956-961.

[17] Peyman S, Hashem A, Rahman E, Ali M, and Abouzar A. 2017. Evaluation of Genotype $\times$ Environment Interaction in Rice Based on AMMI Model in Iran. Rice Science, 2017, 24(3): 173-180.

[18] Pereira HS, Melo LC, Del Peloso MJ, De Faria MJC, Da Costa LGC, Cabrera DL. 2009 Comparison of methods for phenotypic adaptability and stability analysis in com-mon bean. PesqAgropec. 44: 374-383.

[19] Purchase, JL, and Hatting H. 2000. Genotype x environment interaction of winter wheat (Triticumaestivum L.) in South Africa: I. AMMI analysis of yield performance. S. Afr. 1. Plant Soil, 17(3):95-100.

[20] Romagosa I, Fox PN, Garcia del Moral LF, Ramos JM, Garcia del Moral B, Roca de Togores F, and Molina-Cano JL. 1993. Integration of statistical and physiological adaptation in barley cultivars. TheorAppl Genet, 86: 822-826.

[21] Smoliak S, Ditterline RL, Scheetz JD, Holzworth LK, Sims JR, Wiesner JR, Baldridge, D E, Tibke GL. 1990. Common bean. Montana State University, Animal \& Range Sciences Extension Service, Forage extension program, Bozeman, USA.

[22] Wortmann CS. 2006. Phaseolus vulgaris L. (common bean). Record from PROTA4U. Brink, M. \& Belay, G. (Editors). PROTA (Plant Resources of Tropical Africa / Resources vegetables de l'Afrique tropicale), Wageningen, Netherlands.

[23] Yan W, Cornelius PL, Crossa J and Hunt LA. 2001. Two types of GGE biplotsfar analyzing multi-environment trial data. Crop Science 41: 656-663.

[24] Zobel RW, Madison JW, Gauch HG Jr. 1988. Statistical analysis of a yield trial. Agronomy Journal 80: 388-393. 